\title{
Avaliação da partida e operação de filtros anaeróbios tendo bambu como material de recheio
}

\section{Start up Evaluation and Operation of Anaerobic Filters Filled up with Bamboo}

\author{
Adriano Luiz Tonetti \\ Doutor em Saneamento e Ambiente pela Faculdade de Engenharia Civil, Arquitetura e Urbanismo da Universidade Estadual de Campinas (Unicamp)
}

\author{
Bruno Coraucci Filho \\ Professor titular da Faculdade de Engenharia Civil, Arquitetura e Urbanismo da Unicamp \\ José Roberto Guimarães \\ Professor-associado da Faculdade de Engenharia Civil, Arquitetura e Urbanismo da Unicamp \\ Luana Mattos de Oliveira Cruz \\ Doutoranda da Faculdade de Engenharia Civil, Arquitetura e Urbanismo da Unicamp \\ Marcela Soliz Nakamura \\ Engenheira química formada pela Faculdade de Engenharia Química da Unicamp
}

\section{Resumo}

Neste trabalho, foram constituídos três filtros anaeróbios com volume de 500 L preenchidos com anéis de bambu, operando-os com tempo de detenção hidráulica de nove horas. O objetivo foi a determinação do período de partida sem o emprego de inóculo adaptado e a obtenção da eficiência no tratamento de esgoto doméstico, empregando-se um tempo de detenção hidráulica inferior às 12 horas sugeridas pela NBR 7229. Na avaliação do sistema, fez-se uso do carbono orgânico dissolvido, da demanda química de oxigênio, da demanda bioquímica de oxigênio, pH e alcalinidade, evidenciando quanto ao carbono orgânico dissolvido, a necessidade de 19 semanas para que se alcançasse o equilíbrio dinâmico nos reatores. Após esse período, a remoção atingiu 81,4 \pm $6,4 \%$. Os resultados demonstraram que o uso de um recheio alternativo nos filtros anaeróbios possibilitou uma eficiência similar a encontrada com materiais tradicionais, mesmo adotando-se um tempo de detenção hidráulica inferior ao indicado pela norma brasileira.

Palavras-chave: esgoto; tratamento; alternativo; material de recheio; bambu.

\section{Abstract}

In this paper, three anaerobic filters with $500 \mathrm{~L}$ volume were constructed and filled up with bamboo rings, operating with a nine hour hydraulic retention time. The aim was to determinate the start up period without using adapted sludge and reaching efficiency in a wastewater treatment, by deploying hydraulic detention time lower than the 12 hours suggested by the NBR 7229. In the system evaluation, it was used the dissolved organic carbon, chemical oxygen demand, biochemical oxygen demand, $\mathrm{pH}$, and alkalinity, showing in terms of dissolved organic carbon, the need of 19 weeks to reach dynamic equilibrium in the reactors. After this period, the removal achieved $81.4 \pm 6.4 \%$. Results showed that using an alternative package in anaerobic filters made possible to have an efficacy similar to the one reached with traditional materials, even with the hydraulic detention time lower than the one suggested by the Brazilian law.

Keywords: wastewater; treatment; alternative; filling material; bamboo.

Endereço para correspondência: Adriano Luiz Tonetti - Faculdade de Engenharia Civil, Arquitetura e Urbanismo (FEC) da Unicamp - Avenida Albert Einstein, 951 Cidade Universitária "Zeferino Vaz" - Caixa Postal 6.021 - 13083-852 - Campinas (SP), Brasil. Telefone: (19) 3788-2381 - E-mail: altonetti@yahoo.com.br Recebido: 06/07/10 - Aceito: 02/02/11 - Reg. ABES: 07309 


\section{Introdução}

Ao analisar os dados apresentados pelo IBGE (2000) sobre saneamento básico, nota-se uma melhoria nas últimas décadas, garantindo que praticamente toda a população das grandes metrópoles brasileiras seja atendida por rede coletora. Este novo quadro permitiu que, após 1989, sobretudo nas cidades com mais de 300.000 habitantes, os esforços fossem direcionados ao tratamento desses esgotos. Por outro lado, nas pequenas localidades persiste uma deficiência crônica na questão sanitária. Na maioria dos casos, os dejetos são lançados in natura no ribeirão mais próximo ou escorrem no próprio arruamento, contribuindo para a deterioração ambiental e o comprometimento da saúde humana (TONETTI et al, 2010).

Desse modo, buscando contribuir para a solução de tal problema, o Programa de Pesquisas em Saneamento Básico (PROSAB, 2010) tem realizado muitas pesquisas para o desenvolvimento de métodos de tratamento aplicáveis a estes grupamentos populacionais. Um dos sistemas que coube a Universidade Estadual de Campinas (Unicamp) estudar foi o tratamento de esgoto doméstico por filtros anaeróbios (COUTO; FIGUEIREDO, 1992; CAMARGO, 2000; CAMARGO; NOUR, 2001), o qual é uma opção de baixo custo que remove aproximadamente $70 \%$ da matéria orgânica e produz uma quantidade reduzida de iodo. No entanto, para seu uso em escala real, demandase uma avaliação de sua partida sem o emprego de um inóculo, visto que nos locais onde existe a possibilidade de sua instalação há dificuldade em se encontrar um filtro anaeróbio ou tanque séptico em operação para o fornecimento da biomassa adaptada. Outro ponto importante a ser discutido diz respeito ao tempo de detenção hidráulica (TDH), que, segundo a NBR 7229 (1993), deve ser de no mínimo 12 horas, valor este questionado por Além Sobrinho e Said (1991), os quais afirmam que poderia haver sua diminuição à metade.

Ressalta-se também que, segundo van Haandel e Lettinga (1994), um dos empecilhos para a adoção dos filtros anaeróbios em escala real se refere ao custo do material de recheio, que pode ter a mesma ordem de grandeza da própria construção do reator. Por isso, no Brasil, estudaram-se materiais alternativos aos tradicionalmente empregados (pedra britada e anéis plásticos), como anéis de eletroduto cortado, escória de alto-forno e tijolos cerâmicos (CIRNE et al, 2007), demonstrando que torna-se de extremo interesse para o saneamento de pequenas localidades estudos com o emprego de materiais disponíveis na própria imediação da região onde se almeja a instalação de um sistema para o tratamento de esgotos. No caso, em localidades onde o bambu é amplamente disponível, o uso do seu caule cortado em pequenos pedaços como material de recheio pode ser viabilizado.

Deste modo, baseando-se nessas premissas, no presente trabalho objetivou-se a determinação do período de partida de um filtro anaeróbio com recheio de bambu sem o emprego de inóculo adaptado, e a obtenção da eficiência no tratamento do esgoto doméstico ao ser empregado um TDH inferior às 12 horas sugeridas pela norma brasileira (NBR 7229, 1993).

Cabe destacar que, além das tradicionais análises referentes à matéria orgânica (demanda bioquímica de oxigênio - DBO e demanda química de oxigênio - DQO), empregou-se também a sua determinação por meio da concentração do carbono orgânico dissolvido (COD), utilizando-se um aparelho (TOC 5000A-Shimadzu) que possibilita alto grau de precisão e exatidão, além de grande repetição de análises em um curto espaço de tempo.

\section{Material e métodos}

Este projeto foi instalado numa área do Laboratório de Protótipos Aplicados ao Tratamento de Águas e Efluentes da Faculdade de Engenharia Civil, Arquitetura e Urbanismo da Unicamp. O esgoto bruto aplicado nos filtros anaeróbios era proveniente de algumas instalações da universidade e apresentou características típicas de origem doméstica, conforme pode ser constatado pela apreciação da Tabela 1. As amostras empregadas nestas análises eram obtidas imediatamente antes da entrada do líquido nos reatores, sendo originárias de uma caixa de 1.000 L localizada a 3,20 m de altura, que era mantida cheia e com constante circulação de esgoto, visando a manutenção de uma vazão constante no sistema.

O fluxo desse esgoto era direcionado a três filtros anaeróbios. Cada um deles era construído em aço inox com formato cilíndrico e volume total de 500 L. O fundo era cônico e separado da região ocupada pelo meio suporte por uma grade de bambu, funcionando como um compartimento para a distribuição do esgoto. A Figura 1 mostra um esquema e as fotos de um destes reatores.

O meio suporte era constituído de anéis de bambu da espécie Bambusa tuldoides, os quais tinham diâmetro de 0,03 m e eram cortados em tamanhos de aproximadamente 0,05 m de comprimento (CAMARGO, 2000). Após o preenchimento dos reatores com este material, uma média de $74,7 \pm 0,3 \%$ do volume interno era de vazios. Quanto à área superficial dos cavacos de bambu, na Tabela 2, estão apresentados os valores obtidos, comparando-os com outros materiais comumente empregados.

A operação era de fluxo ascendente, com TDH nominal de nove horas, sendo sua vazão controlada duas vezes ao dia. Neste ponto, salienta-se que, desde o princípio da atividade do sistema, adotou-se este tempo de detenção, não tendo sido empregado valores maiores que garantissem uma rápida formação da cultura biológica. O período analítico perdurou por 40 semanas, compreendido entre setembro de 2007 e abril de 2008.

\section{Coleta das amostras e análises laboratoriais}

O esgoto bruto e o efluente dos três filtros anaeróbios foram coletados semanalmente a partir do sistema em estudo. As amostragens 
eram simples e realizadas em tempo suficiente para o enchimento de um frasco de 2 L. Para os filtros anaeróbios, havia uma composição igualitária do efluente gerado nos três reatores. Todas as análises eram realizadas imediatamente após a coleta e feitas no Laboratório de Saneamento da Faculdade de Engenharia Civil, Arquitetura e Urbanismo da UNICAMP, estando baseadas no Standard Methods for the Examination of Water and Wastewater (APHA et al, 2005).

As determinações de COD foram feitas em um analisador de carbono TOC 5000A (Shimadzu). Este equipamento avalia a quantidade de carbono total (CT) e carbono inorgânico (CI) presente em uma amostra aquosa. Para a determinação da concentração de CT, uma alíquota da amostra era injetada e carreada para um tubo de combustão a $680^{\circ} \mathrm{C}$ contendo platina suportada em alumina, no qual o carbono orgânico sofre uma oxidação catalítica resultando em $\mathrm{CO}_{2}$. Para a determinação da concentração de CI, a amostra é injetada e reage apenas com o ácido fosfórico a $25 \%$, sendo que todo $\mathrm{CI}$ é convertido a $\mathrm{CO}_{2}$. O dióxido de carbono produzido, tanto na oxidação catalítica como proveniente de CI, é quantificado por absorção no infravermelho não-dispersivo. As concentrações de CT e CI foram obtidas por interpolação, utilizando curvas analíticas feitas previamente por injeção de padrões. O COD foi encontrado pela subtração de CT e CI. O aparelho possui uma faixa de trabalho que varia entre 4 ppb e 4.000 ppm, com tempo de análise de 4,5 minutos e repetição com desvio de 1\% da escala.

Tabela 1 - Caracterização do esgoto bruto empregado na pesquisa

\begin{tabular}{lc} 
Parâmetro & Média dos resultados \\
$\mathrm{pH}$ & $6,9 \pm 0,3$ \\
Alcalinidade total & $110 \pm 31 \mathrm{mgCaCO} \cdot \mathrm{L}^{-1}$ \\
\hline Oxigênio dissolvido & $0,55 \pm 0,26 \mathrm{mg}^{\mathrm{L}} \mathrm{L}^{-1}$ \\
\hline Sólidos suspensos totais & $115 \pm 50 \mathrm{mg} \cdot \mathrm{L}^{-1}$ \\
DBO & $489 \pm 158 \mathrm{mg} \cdot \mathrm{L}^{-1}$ \\
\hline DQO & $823 \pm 113 \mathrm{mgO}_{2} \cdot \mathrm{L}^{-1}$ \\
DQO filtrada & $627 \pm 176 \mathrm{mgO}_{2} \cdot \mathrm{L}^{-1}$ \\
COD & $161,9 \pm 73,2 \mathrm{mg}^{-L^{-1}}$
\end{tabular}

Tanto para a determinação de COD, como para a de DQO filtra$\mathrm{da}$, as amostras eram inicialmente passadas por membranas Whatman GF/C, com poros de $0,45 \mu \mathrm{m}$, pois o objetivo era uma estimativa do teor de matéria orgânica no líquido filtrado. Este procedimento foi realizado porque o analisador de carbono TOC 5000A não é apto para realizar determinações para amostras brutas, com material particulado em suspensão.

\section{Resultados}

\section{Avaliação da partida dos filtros anaeróbios sem 0 emprego de inóculo}

Após a construção dos filtros anaeróbios, iniciou-se a aplicação do esgoto bruto nesses reatores, sendo que durante o período compreendido pelo experimento, sua temperatura foi de $24,1 \pm 3,1^{\circ} \mathrm{C}$. $\mathrm{O}$ pH médio encontrado para este ponto de coleta e no efluente dos filtros anaeróbios foi de 6,9 $\pm 0,3$ e 6,8 \pm 0,2, respectivamente, e o valor de alcalinidade total de $111 \pm 37 \mathrm{mg} \cdot \mathrm{L}^{-1}$ e $181 \pm 50 \mathrm{mg} \cdot \mathrm{L}^{-1}$.

Por meio dos dados apresentados na Figura 2, verifica-se que, até a oitava semana de operação, o efluente anaeróbio apresentava valores de COD muito próximos aos encontrados no esgoto bruto, demonstrando que ainda não havia a completa formação da cultura

Tabela 2 - Percentagem de vazios e área superficial para alguns materiais empregados como recheio em filtros anaeróbios

\begin{tabular}{lcc|}
\hline Recheio & $\begin{array}{c}\text { Percentagem de } \\
\text { vazios }(\%)\end{array}$ & $\begin{array}{c}\text { Área superficial } \\
\left(\mathrm{m}^{2} \mathrm{~m}^{-3}\right)\end{array}$ \\
\hline Cavacos de bambu & 75 & 91,8 \\
\hline Pedra britada & 55 & 60,1 \\
$\begin{array}{l}\text { Anéis de Raschig em } \\
\text { metal }(2 \text { in)* }\end{array}$ & 92 & 103,0 \\
\hline $\begin{array}{l}\text { Anéis de Pall }(2 \mathrm{in})^{*} \\
\text { *Henley e Seader (2005). }\end{array}$ & 94 & 118,1 \\
\hline
\end{tabular}

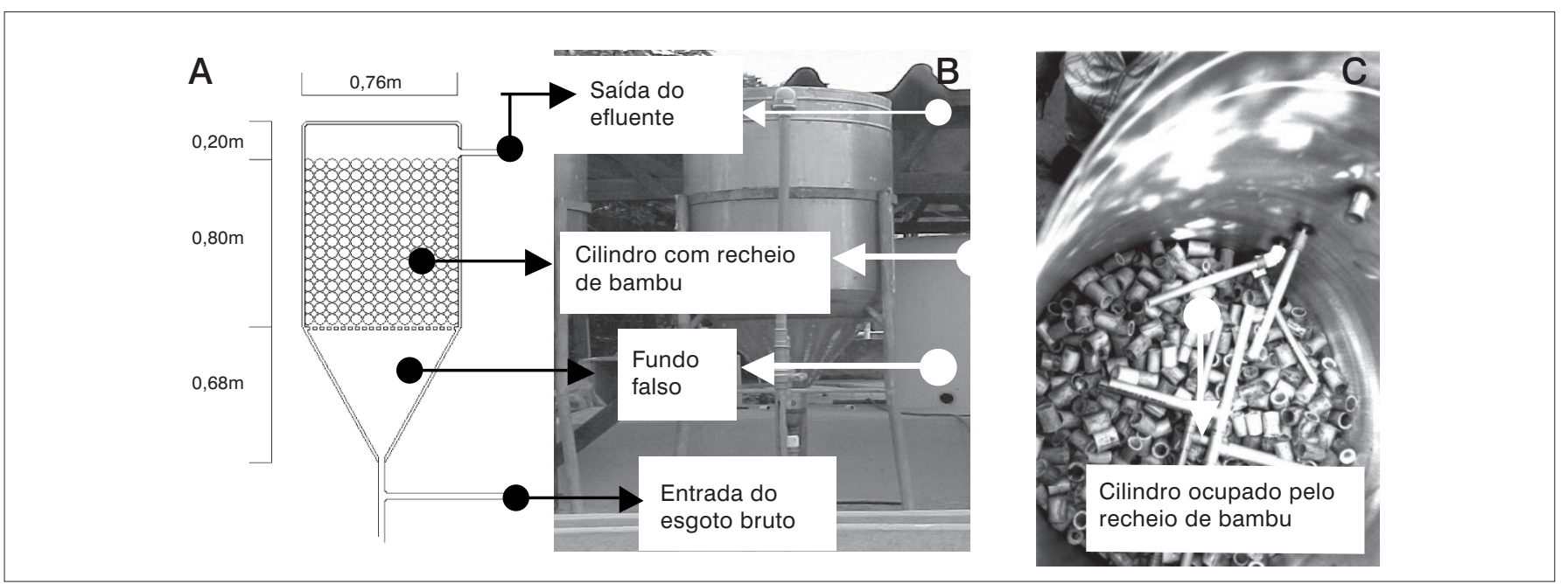

Figura 1 - Esquema de um filtro anaeróbio com recheio de bambu (A) e sua vista externa (B) e interna (C). 


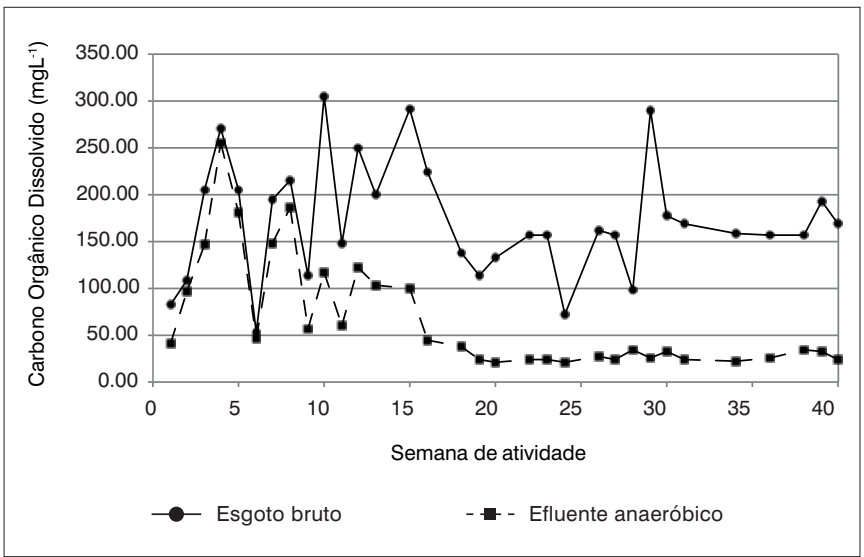

Figura 2 - Concentração de carbono orgânico dissolvido no esgoto bruto e no efluente dos filtros anaeróbios durante o período do experimento.

biológica capaz de degradar os compostos presentes na água residuária. Tal comportamento era esperado, visto que não foi empregado um inóculo para o período de partida.

$\mathrm{Na}$ fase analítica de 40 semanas, a concentração de COD média no esgoto bruto foi de $170,6 \pm 70,4 \mathrm{mg}$. $\mathrm{L}^{-1}$. Para o efluente dos filtros anaeróbios, pode-se considerar que, a partir da $19^{a}$ semana ou aproximadamente após 4,4 meses, aconteceu uma estabilização nos valores de COD em um patamar de concentração, indicando que o sistema atingiu o equilíbrio dinâmico. Esta fase demandou um tempo ligeiramente acima do sugerido por van Haandel e Lettinga (1994), os quais estipulam sua duração em um reator biológico sem o emprego de inóculo entre três e quatro meses, baseando-se nos dados gerados em um conjunto de pesquisas com reatores de, no mínimo, 64 $\mathrm{m}^{3}$ e que possuíam apenas um tratamento preliminar composto por gradeamento e caixa de areia. Salienta-se que, segundo estes autores, o período de partida é o tempo necessário para a obtenção de um efluente com características essencialmente constantes no decorrer da operação do sistema.

Também é possível comparar os dados com àqueles encontrados por Camargo (2000) e Camargo e Nour (2001), que estudaram filtros anaeróbios com TDH de nove horas e necessitaram de um período de partida de 23 semanas, quanto à estabilização dos valores de DQO bruta. Nesse caso, os autores empregaram inóculo na etapa inicial e o esgoto bruto era coletado após os desarenadores de uma estação de tratamento, composta por lagoas de estabilização, passando posteriormente por duas caixas com volume de $1.000 \mathrm{~L}$ que objetivavam a regularização da vazão nos reatores. Por sua vez, Daltro e Povinelli (1990) operaram outro filtro anaeróbio, precedido de um decanto digestor, com TDH de 48 horas e acabaram obtendo uma fase inicial de adaptação de 30 semanas. Esses conjuntos de dados encontrados na literatura acrescidos dos resultados obtidos na presente pesquisa apontam para o fato de que no início da operação de filtros anaeróbios de pequenas dimensões, o não-uso de um inóculo não ocasionou um significativo incremento no seu período de partida. Esta constatação torna-se muito importante ao avaliar que em muitas localidades onde é viável a instalação desse sistema de tratamento não há disponibilidade de inóculo adaptado e, caso haja sua presença, deve-se considerar que sua captação e transporte podem sujeitar a pessoa que a realiza a uma contaminação com patógenos.

No estudo, após a fase operacional inicial, a média da remoção de COD em relação ao esgoto bruto subiu para $81,4 \pm 6,4 \%$, comprovando a grande capacidade do sistema estudado em depurar a água residuária avaliada. Estes dados podem ser melhores visualizados analisando-se a Figura 3, na qual são apresentados semana a semana ao longo de todo o tempo de operação.

Quanto aos valores da DQO, a média encontrada para o esgoto foi de $832 \pm 123 \mathrm{mgO}_{2} \cdot \mathrm{L}^{-1}$. Este dado está ligeiramente acima da faixa considerada como típica por von Sperling (1997), o qual estipula o mínimo de $400 \mathrm{mgO}_{2} \cdot \mathrm{L}^{-1}$ e o máximo de $800 \mathrm{mgO}_{2} \cdot \mathrm{L}^{-1}$ como sendo apropriadas para esgotos de origem doméstica.

No efluente dos filtros anaeróbios, como pode ser verificado por meio dos dados apresentados na Figura 4, a partir da $21^{\text {a }}$ semana os valores de DQO bruta tenderam a se estabilizar em um patamar, tal como ocorreu para as concentrações de COD. Neste novo equilíbrio, a média de remoção passou a $76 \pm 12 \%$, estando ligeiramente abaixo da redução encontrada para os dados de COD.

Esta remoção pode ser comparada com o levantamento apresentado por Pinto (1995), o qual encontrou para uma série de pesquisas em que foram utilizados filtros anaeróbios operados com TDH, que variaram entre seis e oito horas, eficiências médias que oscilaram entre 68 e $79 \%$. Os resultados foram obtidos para filtros operados com vazão constante e como unidades isoladas de tratamento, precedidos apenas de uma etapa preliminar (gradeamento e caixa de areia). Assim, constata-se que os reatores estudados no presente trabalho atingiram resultados comparáveis com a literatura, destacando-se que essa eficiência foi obtida com um recheio de baixo custo, que é o bambu, em contraste com os materiais sintéticos comerciais. Esse recheio alternativo também apresenta grande resistência a longos períodos de uso em filtros anaeróbios, conforme ensaios de resistência realizados por Camargo (2000), Camargo e Nour (2001) e Tonetti (2008). No entanto, cabe destacar que além de serem consideradas a disponibilidade e o baixo custo, também deve ser avaliada a dificuldade de realizar o corte de seu caule, fato que pode inviabilizar a construção de um sistema que possua este material de recheio em médias e largas escalas.

Quanto à média dos valores de DQO filtrada para o esgoto bruto, esta foi de $654 \pm 144 \mathrm{mgO}_{2} \cdot \mathrm{L}^{-1}$, enquanto que, no efluente dos filtros anaeróbios, atingiu $284 \pm 218 \mathrm{mgO}_{2} \cdot \mathrm{L}^{-1}$. Esses dados correspondem, respectivamente, a 79 e $83 \%$ daqueles presentes na DQO bruta. O aumento do percentual encontrado no efluente dos filtros anaeróbios em relação ao esgoto bruto deveu-se, possivelmente, à solubilização da matéria orgânica particulada.

No que tange a DBO do esgoto bruto, obteve-se média de 465 $\pm 161 \mathrm{mg} . \mathrm{L}^{-1}$, sendo que este valor está dentro da faixa considerada 


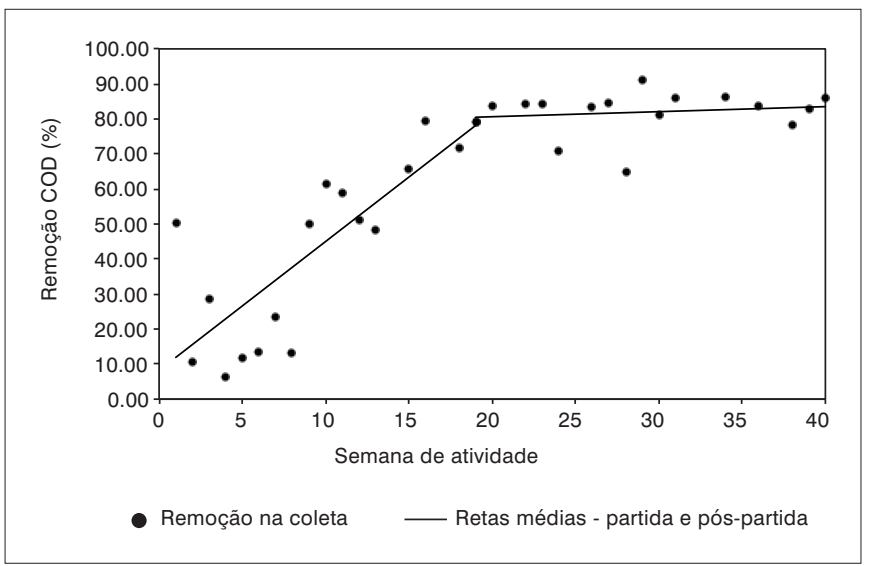

Figura 3 - Remoção dos valores de carbono orgânico (COD) dissolvido do efluente dos filtros anaeróbios em relação ao esgoto bruto durante 0 período do experimento.

como característica para esgotos domésticos para von Sperling (1996), a qual possui os valores mínimos e máximos de $200 \mathrm{mg} \cdot \mathrm{L}^{-1} \mathrm{e}$ $500 \mathrm{mg} . \mathrm{L}^{-1}$, respectivamente. Quanto ao efluente dos filtros anaeróbios, caso sejam considerados os dados gerados após a etapa de partida, tem-se um valor de remoção muito robusto, sendo equivalente a $71 \pm 15 \%$. Este dado está dentro da faixa apresentada por Pinto (1995) em seu levantamento de artigos científicos.

Os resultados foram obtidos com a adoção de um TDH de apenas nove horas, contrastando com a NBR 7229 (1993), que sugere no mínimo uma retenção de 12 horas para o líquido a ser tratado. Assim, aponta-se para a comprovação da veracidade da afirmação de Além Sobrinho e Said (1991), os quais constataram que se poderia diminuir significativamente o TDH sugerido pela norma brasileira, sem acarretar um prejuízo na qualidade do efluente. No entanto, estes dados ainda devem ser vistos com ressalvas, uma vez que as recomendações da NBR 7229 (1993) são aplicáveis a sistemas de porte muito reduzido, nos quais as variações de vazão são extremas.

\section{Conclusões}

Nesta pesquisa, constatou-se que filtros anaeróbios tendo bambu como material de recheio demandaram um período de partida de 4,4

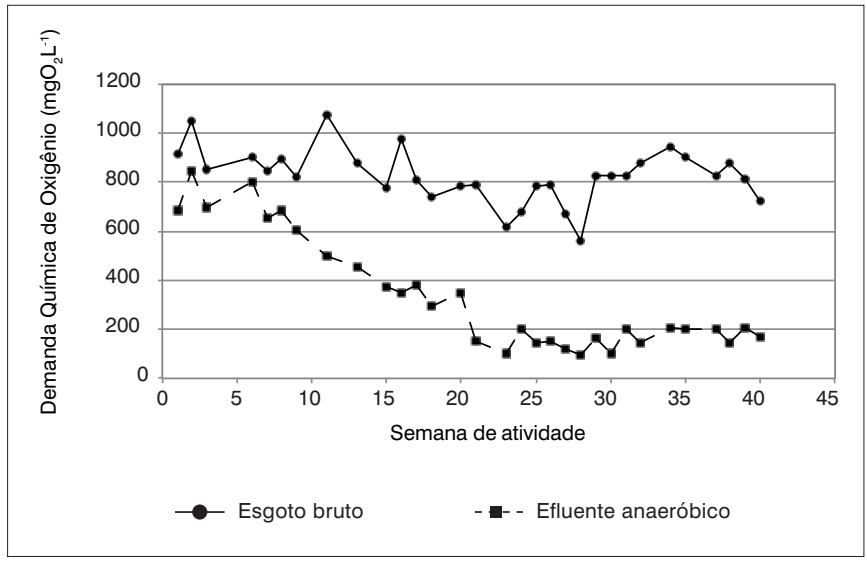

Figura 4 - Demanda química de oxigênio (DQO) bruta no esgoto bruto e no efluente dos filtros anaeróbios durante o período do experimento.

meses. Tal resultado foi compatível com os valores encontrados na literatura, mesmo aos casos em que se empregou um inóculo adaptado (CAMARGO, 2000; DALTRO; POVINELLI, 1990), apontando para que nas situações em que sua construção ocorra em pequena escala, o uso ou não de inóculo não traria benefícios expressivos na diminuição do tempo de partida. No tocante a eficiência do sistema, mesmo empregando-se um TDH inferior ao sugerido pela NBR 7229 (1993) e utilizando-se um material suporte simplificado e alternativo, como é o bambu, os reatores apresentaram uma remoção de matéria orgânica que alcançou a média de 81,4 \pm 6,4\% em termos de COD, $76 \pm$ $12 \%$ em relação à DQO e $71 \pm 15 \%$ em termos de DBO, valores com a mesma ordem de grandeza da literatura consultada.

\section{Agradecimentos}

À Fundação de Amparo à Pesquisa do Estado de São Paulo (FAPESP), ao Conselho Nacional de Desenvolvimento Científico e Tecnológico (CNPq), à Financiadora de Estudos e Projetos (FINEP), à Caixa Econômica Federal e ao PROSAB pelo apoio e financiamento na construção do projeto e em sua manutenção, e à Coordenação de Aperfeiçoamento de Pessoal de Nível Superior (CAPES) pela concessão da bolsa de doutorado.

\section{Referências}

ALÉM SOBRINHO, P.; SAID, M. A. Decanto digestor e filtro anaeróbio, experiência de campo. Proposições para alteração do método de dimensionamento do filtro anaeróbio proposto pela NBR 7229. In: Congresso Brasileiro de Engenharia Sanitária e Ambiental, Associação Brasileira de Engenharia Sanitária (Abes), 1991.

APHA/AWWA/WEF. Standard methods for the examination of water and wastewater. 19a edição. Nova lorque: American Public Health Association, 2005. 1268p.
CAMARGO, S.A.R. Filtro anaeróbio com enchimento de bambu para tratamento de esgotos sanitários: avaliação da partida e operação. 2000. 170p. Dissertação (Mestrado em Saneamento e Ambiente). Faculdade de Engenharia Civil da Universidade Estadual de Campinas, Campinas, 2000.

CAMARGO, S. A. R.; NOUR, E. A. A. Bamboo as an anaerobic medium: effect of filter column height. Water Science and Technology, v. 44, n. 4, p. 63-70, 2001. 
CIRNE, A. R. C.; ANDRADE NETO, C. O.; MELO, H. N. S.; ARAÚJO, A. L. C. Avaliação comparativa de filtros anaeróbios contendo diferentes materiais de enchimento. In: 24a Congresso Brasileiro de Engenharia Sanitária e Ambiental, Associação Brasileira de Engenharia Sanitária (Abes), 2007.

COUTO, L. C. C.; FIGUEIREDO, R. F. Filtro anaeróbio com bambu para tratamento de esgotos domésticos. In: Congreso Interamericano de Ingeniería Sanitaria y Ambiental. AIDIS, La Habana, Cuba, p.329-340. 1992.

DALTRO, J.; POVINELLI, J. Avaliação da altura da camada suporte de filtros anaeróbios piloto no tratamento de esgotos sanitários. In: Congresso Brasileiro de Engenharia Sanitária e Ambiental, Associação Brasileira de Engenharia Sanitária (Abes), 1990

HENLEY E. J.; SEADER, J. D. Separation Process Principles. 2nd edition. John Wiley \& Sons, Inc., 2005.

INSTITUTO BRASILEIRO DE GEOGRAFIA E ESTATÍSTICA (IBGE). Pesquisa Nacional de Saneamento Básico. Rio de Janeiro. 2000.

NBR 7229. Projeto, construção e operação de tanques sépticos. São Paulo: ABNT, 1993

PINTO, J. D. S. Tratamento de esgotos sanitários em filtros anaeróbios utilizando escória de alto forno como meio suporte. Dissertação
(Mestrado em Saneamento e Ambiente). Universidade Federal de Minas Gerais, Belo Horizonte, 1995.

Programa de pesquisa em saneamento básico (PROSAB). Disponíve em: <http://www.finep.gov.br/prosab/index.html>. Acesso em: 23 out 2010

TONETTI, A. L. Tratamento de esgotos pelo sistema combinado filtro anaeróbio e filtros de areia. 140p. Tese (Doutorado). Faculdade de Engenharia Civil, Arquitetura e Urbanismo, Universidade Estadual de Campinas, Campinas, 2008

TONETTI, A. L.; CORAUCCI FILHO, B.; BERTONCINI, E. I.; OLIVEIRA, R. A.; STEFANUTTI, R. Avaliação de um sistema simplificado de tratamento de esgotos visando a utilização em áreas rurais. Revista Brasileira de Engenharia Agrícola e Ambiental, v.14, n.2, p.227-234, 2010.

VAN HAANDEL, A.C.; LETTINGA, G. Tratamento anaeróbio de esgotos: um manual para regiões de clima quente. Campina Grande: Ed. Epigraf, 1994.

VON SPERLING, M. Princípios básicos do tratamento de esgotos. $1^{a}$ edição. Belo Horizonte: UFMG, 1997. 